\title{
PENGARUH PARTISIPASI PENYUSUNAN ANGGARAN, KOMITMEN ORGANISASI, DAN PROFESIONALISME TERHADAP KINERJA MANAJERIAL BANK BUMN KOTA PALEMBANG
}

\author{
Pipit Fitri Rahayu \\ Universitas Tridinati, Palembang, Indonesia \\ e-mail: pipitfitrirahayu@univ-tridinanti.ac.id
}

\begin{abstract}
The purpose of this study are to determine the effect of the participation in composing budget, organizational commitment, and professionalism on the performance of the BUMN Bank in Palembang. In addition, this institution is a company that also has branch offices, financial managers, operational managers, credit managers, and corporate finance such as Bank Mandiri, Bank Negara Indonesia. (BNI) and the State Savings Bank (BTN) of Palembang city which prioritizes 36 people. The sample that used is 36 people using a census is all the populations sampled. Technique to analyze data are multiple regression analysis with SPSS 21 software tools. The results of the study partially indicate that: (1) budget participation is positive and significant toward the managerial performance of Palembang City BUMN Bank, (2) organizational commitment is positive and significant toward managerial performance Palembang City BUMN Bank, and (3) professionalism that has a significant positive effect on the managerial performance of the BUMN Bank of Palembang City. And the results of the simultaneous testing also show that budget participation, organizational commitment, and professionalism have a positive and significant effect on the performance of managers of BUMN Bank Palembang City.
\end{abstract}

Keywords: Participation in budgeting, organizational commitment, professionalism, managerial performance. 



\section{PENDAHULUAN}

BUMN (Badan Usaha Milik Negara)

adalah badan usaha yang seluruh atau sebagian besar modalnya dimiliki oleh negara melalui penyertaan secara langsung yang berasal dari kekayaan negara yang dipisahkan. BUMN memiliki berbagai macam atau jenis yang berdasarkan UndangUndang Republik Indonesia No.19 Tahun 2003 tentang BUMN, yang memiliki dua bentuk yaitu badan Usaha Perseroan (Persero) dan Badan Usaha Umum (Perum). Dalam menjalankan tugasnya, BUMN sering menghadapi berbagai permasalahan yang disebabkan oleh adanya penurunan kinerja manajerial yang akan berdampak pada tidak tercapainya tujuan. Sehingga, kinerja manajerial harus dikendalikan sebaik mungkin secara efektif dan efisien. Dengan kinerja manajerial yang baik, maka diharapkan dapat mempertahankan kelangsungan hidup perusahaan. Disamping itu, anggaran merupakan komponen penting dalam perusahaan. Pentingnya fungsi anggaran sebagai perencana dan pengendali perusahaan menjadikan penganggaran sebagai hal yang penting bagi keberhasilan perusahaan (Sinuraya, 2009).

Mengingat begitu pentingnya partisipasi penyusunan anggaran perbankan khususnya Badan Usaha Milik Negara (BUMN) kota Palembang serta adanya masalah yang berkaitan dengan temuantemuan penelitian yang berbeda tersebut, maka penulis merasa tertarik untuk melakukan penelitian yang berjudul

Pengaruh Partisipasi Penyusunan Anggaran, Komitmen Organisasi, dan Profesionalisme Terhadap Kinerja Manajerial Bank BUMN Kota Palembang.

\section{MASALAH DAN TUJUAN}

Berdasarkan latar belakang masalah tersebut maka dapat dirumuskan masalah sebagai berikut:

1. Apakah partisipasi penyusunan anggaran berpengaruh secara parsial terhadap kinerja manajerial pada Bank BUMN Kota Palembang ?
2. Apakah komitmen organisasi berpengaruh secara parsial terhadap kinerja manajerial Bank BUMN Kota Palembang?

3. Apakah profesionalisme berpengaruh secara parsial terhadap kinerja manajerial Bank BUMN Kota Palembang ?

4. Apakah partisipasi penyusunan anggaran, komitmen organisasi, dan profesionalisme berpengaruh secara simultan terhadap kinerja manajerial Bank BUMN Kota Palembang ?

\section{Tujuan Penellitian}

Adapun tujuan dalam penelitian ini sebagai berikut:

1. Untuk mengetahui seberapa besar partisipasi penyusunan anggaran terhadap kinerja manajerial Bank BUMN Kota Palembang.

2. Untuk mengetahui seberapa besar komitmen organisasi terhadap kinerja manajerial Bank BUMN Kota Palembang.

3. Untuk mengetahui seberapa besar profesionalisme terhadap kinerja manajerial Bank BUMN Kota Palembang.

4. Untuk mengetahui seberapa besar partisipasi penyusunan anggaran, komitmen organisasi, dan profesionalisme terhadap kinerja manajerial Bank BUMN Kota Palembang.

\section{KAJIAN PUSTKA \\ Teori Agensi}

Teori Agensi dikembangkan oleh Jensen and Meckling pada tahun 1976. Teori ini menjelaskan hubungan antara dua atau lebih individu, kelompok atau organisasi yang memberi wewenang dengan pihak yang menerima wewenang dalam bentuk kontrak kerja yang telah disepakati. Menurut DeGeorge pada tahun 1992 dalam jurnal Smith and Bertozzi (1998) menjelaskan bahwa hubungan prinsipal dan agen berakar pada teori ekonomi, teori sosiologi, teori keputusan dan teori 
organisasi. Salah satu pihak (principal) membuat suatu kontrak, baik secara implisit maupun eksplisit dengan pihak lain (agent) dengan harapan bahwa agen akan melakukan pekerjaan seperti yang diinginkan oleh prinsipal atau dalam hal terjadi pendelegasian wewenang (Asmara, 2010).

Hubungan prinsipal dengan agen terjadi jika tindakan seseorang berdampak pada orang lain atau jika seseorang bergantung pada orang lain. Menurut Anthony dan Govindarajan (1988) menyatakan bahwa teori agensi menjelaskan fenomena yang terjadi apabila atasan mendelegasikan wewenangnya kepada bawahan untuk melakukan suatu tugas atau otoritas dalam membuat keputusan. Pada intinya partisipasi anggaran akan menyebabkan bawahan memberikan informasi yang dimilikinya untuk membantu organisasi. Sebelum dilakukannya penyusunan anggaran, terlebuh dahulu dibuat kesepakatan antara agen dan prinsipal mengenai arah dan prioritas anggaran yang nantinya akan dijadikan sebagai pedoman dalam penyusunan anggaran.

\section{Kerangka Pemikiran}

Gambar 2.1

Bagan Kerangka Berfikir

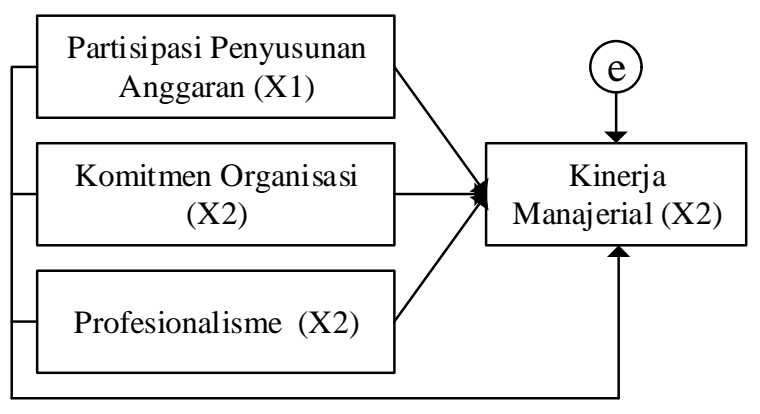

Sumber: Data yang diolah (2018)

\section{Hipotesis}

adalah:

Hipotesis dalam penelitian ini

H1 : Partisipasi penyusunan anggaran berpengaruh secara parsial terhadap kinerja manajerial
H2 : Komitmen organisasi berpengaruh secara parsial terhadap kinerja manajerial

H3 : Profesionalisme berpengaruh secara parsial terhadap kinerja manajerial

H4 : Partisipasi penyusunan anggaran, komitmen organisasi dan profesionalisme berpengaruh secara simultan terhadap kinerja manajerial.

\section{METODOLOGI PENELITIAN Ruang Lingkup Penelitian}

Penelitian ini dilakukan pada Badan Usaha Milik Negara di Kota Palembang yanh bergerak dalam bidang Jasa (perbankan) yang terdiri dari Bank Rakyat Indonesia (BRI), Bank Mandiri, Bank Negara Indonesia (BNI) dan Bank Tabungan Negara (BTN). Data yang digunakan dalam penelitian ini adalah data primer pada tahun 2018. Sedangkan objek penelitian adalah manajer yang terlibat dalam penyusunan anggaran yang terdiri dari kepala cabang, manajer keuangan, manajer operasional, manajer kredit, bagian akuntansi dan manajer pemasaran.

\section{Jenis dan Sumber Data}

Jenis data yang digunakan dalam penlitian ini adalah data primer tahun 2018, sedangkan sumber datanya diperoleh berdasarkan pertanyaan dalam bentuk kuesioner yang diisi oleh responden.

\section{Populasi dan Sampel}

Populasi dalam penelitian ini adalah seluruh karyawan bank BUMN yang turut serta dalam partisipasi anggaran diantaranya kepala cabang, manajer keuangan, manajer operasional, manajer kredit, bagian akuntansi dan manajer pemasaran dilingkungan Bank Rakyat Indonesia (BRI), Bank Mandiri, Bank Negara Indonesia (BNI) dan Bank Tabungan Negara (BTN) kota Palembang yang berjumlah 36 orang. Adapun sampel yang digunakan berjumlah 36 orang dengan menggunakan sensus yaitu semua populasi dijadikan sampel. 
Tabel 3.1

Daftar Bank BUMN di Kota Palembang

\begin{tabular}{|l|l|c|c|}
\hline No. & Nama Bank BUMN & $\begin{array}{c}\text { Jumlah } \\
\text { Cabang }\end{array}$ & $\begin{array}{c}\text { Jumlah } \\
\text { Orang }\end{array}$ \\
\hline 1. & Bank Mandiri & 2 & 12 \\
\hline 2. & Bank BNI & 1 & 6 \\
\hline 3. & Bank BRI & 2 & 12 \\
\hline 4. & Bank BTN & 1 & 6 \\
\hline Total & & 36 \\
\hline
\end{tabular}

Sumber: Data yang diolah (2018)

\section{HASIL DAN PEMBAHASAN}

\section{Hasil Penleitian}

\section{Gambaran Umum Objek Penelitian}

Penelitian ini dilakukan pada Bank BUMN di kota Palembang. Bank Persero (BUMN) merupakan bank yang sebagian atau seluruh sahamnya dimiliki oleh Pemerintah Republik Indonesia. Bank BUMN terdiri dari:

Tabel 4.1

Bank BUMN di Palembang

\begin{tabular}{|c|c|c|c|}
\hline \\
\hline No. & Nama Bank & Unit Kerja & $\begin{array}{c}\text { Alamat Kantor } \\
\text { Cabang }\end{array}$ \\
\hline 1. & Bank Mandiri & $\begin{array}{l}\text { - Sudirman } \\
\text { - Arief }\end{array}$ & $\begin{array}{l}\text { - Jl. Jend } \\
\text { Sudirman No. } \\
\text { 419 Palembang } \\
\text { - J1. Kapten A. } \\
\text { Rivai No. } 27 \\
\text { Palembang } \\
\end{array}$ \\
\hline 2. & $\begin{array}{l}\text { Bank Rakyat } \\
\text { Indonesia } \\
\text { (BRI) }\end{array}$ & $\begin{array}{l}\text { - Riva'i } \\
\text { - Sriwijaya }\end{array}$ & $\begin{array}{l}\text { - J1. Kapten A. } \\
\text { Rivai No. } 15 \\
\text { Palembang } \\
\text { - J1. Letkol } \\
\text { Iskandar No. } 27 \\
\text { Palembang }\end{array}$ \\
\hline 3. & $\begin{array}{l}\text { Bank Negara } \\
\text { Indonesia } \\
\text { (BNI) }\end{array}$ & Musi & $\begin{array}{lr}\text { J1. Jend } \\
\text { Sudirman No. } \\
\text { 132 Palembang }\end{array}$ \\
\hline 4. & $\begin{array}{l}\text { Bank } \\
\text { Tabungan } \\
\text { Negara } \\
\text { (BTN) }\end{array}$ & $\begin{array}{l}\text { KC } \\
\text { Palembang }\end{array}$ & $\begin{array}{lr}\text { Jl. } & \text { Jend } \\
\text { Sudirman Km Km } \\
4,5 \quad \text { No. } 125 \\
\text { Palembang }\end{array}$ \\
\hline
\end{tabular}

Sumber: Data yang diolah, 2018

\section{Hasil Persamaan Regresi Berganda}

Hasil persamaan regresi berganda dalam penelitian ini adalah:

$$
Y=5.685+0.212\left(X_{1}\right)+0.415\left(X_{2}\right)+0.376\left(X_{3}\right)+\varepsilon
$$

Dari persamaan diatas dapat disimpulkan sebagai berikut:

\section{a. Nilai Konstanta}

Nilai konstanta sebesar 5.685 hal ini menunjukkan bahwa variabel bebas (X1, $\mathrm{X} 2$, dan X3) yang terdiri dari Partisipasi penyusunan anggaran, komitmen organisasi, dan profesionalisme mampu memberikan kontribusi yang besar dalam mempengaruhi kinerja manajerial (variabel terikat) .

b. Nilai Variabel X1 (Partisipasi Penyusunan Anggaran)

Nilai variabel X1 (Partisipasi Penyusunan Anggaran) sebesar 0.212 artinya partisipasi penyusunan anggaran memberikan kontribusi positif dalam memengaruhi kinerja manajerial sebesar 0,212 .

c. Nilai Variabel X2 (Komitmen Organisasi)

Nilai Variabel X2 (Komitmen Organisasi) sebesar 0.415 artinya komitmen organisasi memberikan kontribusi positif dalam memengaruhi kinerja manajerial sebesar 0.415 .

d. Nilai Variabel X3 (Profesionalisme) Nilai Variabel X3 (Profesionalisme) sebesar 0.376 artinya profesionalisme memberikan kontribusi positif dalam memengaruhi kinerja manajerial sebesar 0.376 .

\section{Hasil Uji Koefisien Determinasi $\left(\mathbf{R}^{\mathbf{2}}\right)$}

Berdasarkan hasil uji koefisien determinasi dilihat pada tabel berikut:

Tabel 4.7

Hasil Uji Koefisien Determinasi Adjusted $R^{2}$ Model Summary ${ }^{b}$

\begin{tabular}{|c|c|c|c|c|}
\hline Model & $\mathbf{R}$ & $\begin{array}{c}\mathbf{R} \\
\text { Square }\end{array}$ & $\begin{array}{c}\text { Adjusted R } \\
\text { Square }\end{array}$ & $\begin{array}{c}\text { Std. Error of } \\
\text { the Estimate }\end{array}$ \\
\hline 1 & $.956^{\mathrm{a}}$ & .913 & .905 & .841 \\
\hline
\end{tabular}

a. Predictors: (Constant), Profesionalisme, Partisipasi Penyusunan Anggaran, Komitmen Organisasi

b. Dependent Variable: Kinerja

Manajerial

Sumber: Data olahan SPSS, 2018

Berdasarkan tabel 4.8 di atas, terlihat bahwa nilai $\mathrm{R}$ yang didapatkan sebesar 0.956 atau 95,6 \%. Hal ini menunjukan bahwa korelasi atau hubungan antara Kinerja Manajerial Bank BUMN Kota Palembang (variabel dependen) dengan nilai variabel 
independennya (Partisipasi penyusunan anggaran, komitmen organisasi, dan profesionalisme) termasuk dalam kategori kuat.

Angka koefisien determinasi $\mathrm{R}^{2}$ yang dihasilkan adalah sebesar 0.913. Hal ini berarti 91,3 \% variasi dari Kinerja Manajerial Bank BUMN Kota Palembang dijelaskan oleh Partisipasi penyusunan anggaran, komitmen organisasi, dan profesionalisme yang digunakan dalam persamaan regresi. Sedangkan sisanya yaitu sebesar 8,7\% dijelaskan oleh variabel lain yang tidak disertakan dalam model penelitian ini.

\section{Hasil Uji Statistik F}

Hasil penelitian mengenai uji $F$ variabel dependen terhadap variabel independen dalam penelitian ini dilihan pada tabel berikut:

Tabel 4.8

Hasil Uji F Variabel Independen terhadap Variabel Dependen

ANOVA $^{b}$

\begin{tabular}{|l|r|r|r|r|r|}
\hline Model & $\begin{array}{r}\text { Sum of } \\
\text { Squares }\end{array}$ & df & $\begin{array}{c}\text { Mean } \\
\text { Square }\end{array}$ & F & Sig. \\
\hline $1 \quad$ Regression & 238.365 & 3 & 79.455 & 112.468 & $.000^{\mathrm{a}}$ \\
Residual & 22.607 & 32 & .706 & & \\
Total & 260.972 & 35 & & & \\
\hline
\end{tabular}

a. Predictors: (Constant), Profesionalisme,

Partisipasi Penyusunan Anggaran, Komitmen

Organisasi

b. Dependent Variable: Kinerja

Manajerial

Sumber: Data Olahan SPSS, 2018.

Dari tabel 4.9 diatas, nilai signifikan lebih kecil dari $0.05(0.000<0.05)$, karena $F_{\text {hitung }}>F_{\text {tabel }}(112,468>2,87)$, maka model regresi dapat digunakan untuk memprediksi kinerja manajerial Bank BUMN kota Palembang atau dapat dikatakan bahwa variabel X1 (Partisipasi penyusunan anggaran), X2 (Komitmen organisasi), dan X3 (Profesionalisme) secara bersama-sama berpengaruh signifikan terhadap variabel $\mathrm{Y}$ (Kinerja Manajerial Bank BUMN kota Palembang).

\section{Hasil Uji Statistik t}

Uji $t$ dilakukan dengan membandingkan antara $t$ hitung dengan $t$ tabel, dimana nilai $t_{\text {tabel }}$ dalam penelitian ini 2.028 dengan tingkat signifikan 5\% kriteria pengujian yang dilakukan adalah sebagai berikut:

a. Jika $\mathrm{t}_{\text {hitung }}>\mathrm{t}$ tabel $(\mathrm{n}-\mathrm{k}-\mathrm{l})$, jika $p$ value $<$ 0,05 maka Ho ditolak

b. Jika $\mathrm{t}_{\text {hitung }}<\mathrm{t}$ tabel $(\mathrm{n}-\mathrm{k}-\mathrm{l})$, jika $P$ value $>$ 0.05 maka Ho diterima

Dari hasil penelitian didapatkan bahwa koefisien regresi, nilai $\mathrm{t}$ dan signifikansi secara parsial adalah sebagai berikut:

Tabel 4.9

Hasil Uji Parsial (Uji t)

Coefficients $^{\mathrm{a}}$

\begin{tabular}{|c|c|c|c|c|c|}
\hline \multirow[t]{2}{*}{ Model } & \multicolumn{2}{|c|}{$\begin{array}{l}\text { Unstandardi } \\
\text { zed } \\
\text { Coefficients }\end{array}$} & \multirow{2}{*}{\begin{tabular}{|c|}
$\begin{array}{c}\text { Standardi } \\
\text { zed } \\
\text { Coefficien } \\
\text { ts }\end{array}$ \\
Beta
\end{tabular}} & \multirow[t]{2}{*}{$\mathbf{T}$} & \multirow[t]{2}{*}{ Sig } \\
\hline & B & $\begin{array}{l}\text { Std. } \\
\text { Error }\end{array}$ & & & \\
\hline 1 (Constant) & 5.685 & 1.321 & & $\begin{array}{r}4.30 \\
2\end{array}$ & $\begin{array}{r}.00 \\
0\end{array}$ \\
\hline $\begin{array}{l}\text { Partisipasi } \\
\text { Penyusunan } \\
\text { Anggaran }\end{array}$ & .212 & .082 & .242 & $\begin{array}{r}2.60 \\
5\end{array}$ & $\begin{array}{r}.01 \\
4\end{array}$ \\
\hline $\begin{array}{l}\text { Komitmen } \\
\text { Organisasi }\end{array}$ & .415 & .069 & .600 & $\begin{array}{r}5.96 \\
7\end{array}$ & $\begin{array}{r}.00 \\
0\end{array}$ \\
\hline $\begin{array}{l}\text { Profesionali } \\
\text { sme }\end{array}$ & .376 & .156 & .185 & $\begin{array}{r}2.40 \\
6 \\
\end{array}$ & $\begin{array}{r}.02 \\
2 \\
\end{array}$ \\
\hline
\end{tabular}

a. Dependent

Variable: Kinerja

Manajerial

Sumber: Data Olahan SPSS, 2018.

Berdasarkan hasil pengujian parsial (uji t) dari tabel 4.10 diatas, dapat disimpulkan bahwa variabel partisipasi penyusunan anggaran memiliki nilai $\mathrm{t}_{\text {hitung }}>$ $\mathrm{t}$ tabel dimana $2.605>2.028$ dengan tingkat signifikani $0.014>0.05$. Hal ini berarti variabel $\mathrm{X}_{1}$ yaitu partisiasi penyusunan anggaran berpengaruh signifikan terhadap kinerja manajerial. begitu juga dengan variabel komitmen organisasi memiliki nilai $\mathrm{t}_{\text {hitung }}>\mathrm{t}$ tabel dimana $5.967>2.028$ dengan tingkat signifikansi $0.000>0.05$. Hal ini berarti variabel $\mathrm{X}_{2}$ yaitu komitmen 
organisasi berpengaruh signifikan terhadap kinerja manajerial. Dan variabel profesionalisme memiliki nilai $\mathrm{t}_{\text {hitung }}>\mathrm{t}_{\text {tabel }}$ dimana $2.406>2.028$ dengan tingkat signifikansi $0.022>0.05$. Hal ini berarti variabel $\mathrm{X}_{3}$ yaitu profesionalisme berpengaruh signifikan terhadap kinerja manajerial.

\section{Pembahasan}

\section{Partisipasi Penyusunan Anggaran Terhadap Kinerja Manajerial}

Dari hasil pengujian secara parsial, variabel partisipasi penyusunan anggaran memiliki nilai $\mathrm{t}$ hitung $>\mathrm{t}$ tabel dimana $2.605>$ 2.028 dengan tingkat signifikansi $0.014>$ 0.05 sehingga dapat dinyatakan bahwa Partisipasi penyusunan anggaran berpengaruh secara signifikan terhadap kinerja manajerial.

Hasil penelitian ini konsisten dengan penelitian yang dilakukan oleh Kusuma (2016), Moheri dan Arifah (2015), Setyorini, Hasthoro, dan Wicaksono (2013), Himawan dan Ika S (2010), Dianawati (2009), Sinuraya (2009), dan Yusfaningrum dan Ghozali (2005). Hal ini menunjukkan bahwa partisipasi dapat meningkatkan kinerja manajerial, artinya semakin tinggi partisipasi anggaran maka akan semakin tinggi pula kinerja manajerial. Namun, tidak pada penelitian yang dilakukan oleh Supono dan Indriantoro (1998) yang menyatakan bahwa partisipasi dalam penyusunan anggaran tidak mempunyai pengaruh secara langsung terhadap kinerja manajerial, hal ini dikarenakan keefektifan anggaran partisipatif tidak hanya memerlukan keterlibatan para manajer pada lavel yang lebih rendah, melainkan juga perlu adanya pendelegasian wewenang kepada mereka, sehingga mereka mempunyai wewenang yang lebih besar untuk mempengaruhi penyusunan target anggaran yang menjadi pedoman penilaian kinerja mereka.

Hasil penelitian ini memberikan dukungan terhadap teori agensi dengan menjelaskan bahwa sebelum dilakukannya penyusunan anggaran, terlebuh dahulu dibuat kesepakatan antara agen dan prinsipal mengenai arah dan prioritas anggaran yang nantinya akan dijadikan sebagai pedoman dalam penyusunan anggaran. Sehingga partisipasi anggaran akan menyebabkan bawahan memberikan informasi yang dimilikinya untuk membantu organisasi.

\section{Komitmen Organisasi Terhadap Kinerja Manajerial}

Dari hasil pengujian secara parsial, variabel komitmen organisasi memiliki nilai $\mathrm{t}$ hitung $>\mathrm{t}$ tabel dimana $5.967>2.028$ dengan tingkat signifikani $0.000>0.05$ sehingga dapat dinyatakan bahwa komitmen organisasi berpengaruh secara signifikan terhadap kinerja manajerial.

Hasil penelitian ini konsisten dengan penelitian yang dilakukan oleh, Himawan dan Ika S (2010), Kamila, Taufik, dan darlis, Sumarno (2005), Putri (2008), dan Setyorini, Hasthoro dan Wicaksono (2013). Hal ini menunjukkan bahwa dalam komitmen organisasi yang lebih besar, maka partisipasi anggaran akan meningkatkan kinerja manajerial.

Hasil penelitian ini memberikan dukungan terhadap teori agensi dimana naik atau turunnya anggaran tergantung pada apakah individu memilih mengejar kepentingannya sendiri atau justru bekerja untuk kepentingan organisasi, dengan kata lain bahwa komitmen organisasi mampu mempengaruhi hubungan partisipasi anggaran.

\section{Profesionalisme Terhadap Kinerja Manajerial}

Dari hasil pengujian secara parsial, variabel profesionalisme memiliki nilai $t$ hitung $>\mathrm{t}$ tabel dimana $2.406>2.028$ dengan tingkat signifikani $0.022>0.05$ sehingga dapat dinyatakan bahwa profesionalisme berpengaruh secara signifikan terhadap kinerja manajerial.

Hasil penelitian ini juga sejalan dengan penelitian yang dilakukan oleh Siahaan (2010). Hal ini menunjukkan bahwa seorang manajerial dapat bertindak lebih profesional sesuai dengan kemampuan dan keahlian serta karakteristik yang dimiliki 
dalam penyusunan anggaran. Oleh karena itu, setiap profesi memiliki tingkat beban dan tuntutan pekerjaan yang berbeda-beda, namun dalam setiap profesi tersebut tentunya menuntut hasil kinerja yang samasama baik dalam bidangnya masing-masing.

\section{Partisipasi Penyusunan Anggaran, Komitmen Organisasi, dan Profesionalisme Terhadap Kinerja Manajerial}

Dari hasil pengujian secara simultan variabel partisipasi penyusunan anggaran, komitmen organisasi, dan profesionalisme terhadap kinerja manajerial menunjukkan hasil bahwa $F_{\text {hitung }}>F_{\text {tabel }}$ yakni $112,468>$ 2,87 dengan tingkat signifikansi $0.000<0.05$ maka partisipasi penyusunan anggaran, komitmen organisasi, dan profesionalisme secara simultan berpengaruh signifikan terhadap kinerja manajerial.

\section{KESIMPULAN DAN SARAN Kesimpulan}

Berdasarkan hasil pengujian hipotesis dengan menggunakan alat analisis SPSS dari jawaban responden dalam penelitian ini dapat ditarik kesimpulan sebagai berikut:

1. Dari hasil pengujian secara parsial, variabel partisipasi penyusunan anggaran berpengaruh positif dan signifikan terhadap kinerja manajerial.

2. Dari hasil pengujian secara parsial, variabel komitmen organisasi berpengaruh positif dan signifikan terhadap kinerja manajerial.

3. Dari hasil pengujian secara parsial, variabel profesionalisme berpengaruh positif dan signifikan terhadap kinerja manajerial.

4. Dari hasil pengujian secara simultan, variabel partisipasi penyusunan anggaran, komitmen organisasi, dan profesionalisme berpengaruh positif dan signifikan terhadap kinerja manajerial.

\section{Saran}

Berdasarkan hasil penelitian dan kesimpulan diatas maka pada penelitian ini memberikan rekomendasi antara lain :

1. Penelitian selanjutnya diharapkan dapat melakukan penelitian dengan populasi yang lebih luas misalnya penelitian dilakukan pada pemerintahan sehingga jumlah sampel yang dihasilkan banyak.

2. Penelitian selanjutnya diharapkan agar dapat menambah variabel-variabel lain seperti senjangan anggaran. Sehingga penelitian selanjutnya dapat memberikan kontribusi dalam meningkatkan pemahaman dan kemampuan terhadap pengembangan sistem perencanaan dan pengendalian manajemen.

\section{DAFTAR PUSTAKA}

Anthony, Robert N. dan Govindanrajan, Vijay. (Penerjemah: Kurniawan Tjakrawala dan Krista), 2005. Sistem Pengendalian Manajemen. Edisi 1. Jakarta : Penerbit Salemba Empat.

Asmara, Jhon Andra. 2010. Analisis Perubahan Alokasi Belanja Dalam Anggaran Pendapatan dan Belanja Daerah (APBA) Provinsi Nanggroe Aceh Darussalam. Jurnal Telaah \& Riset Akuntansi. Vol. 3 No. 2 Juli 2010, Hal. 155-172.

Dianawati, Eris. 2009. Pengaruh Partisipasi Penyusunan Anggaran Terhadap Kinerja Manajerial: Komitmen Organisasi Dan Job Related Stress Sebagai Variabel Intervening. Jurnal Ekonomi Moderasi, Vo. 5, No. 1, Februari 2009.

Himawan, Albertus Kukuh., dan Ika S, Ardianu. 2010. Pengaruh Komitmen Organisasi, Gaya Kepemimpinan dan Job Relevant Information (JRI) Terhadap Hubungan Antara Partisipasi Anggaran dan Kinerja Manajerial (Studi Empiris pada BPR di Kota Semarang). Jurnal Ekonomi dan Bisnis. Vol. 5, No. 9 April 2010. 
Kamilah, Faizah., Taufik, Taufeni., Darlis, Edfan. Pengaruh Partisipasi Anggaran Terhadap Kinerja Manajerial Dengan Komitmen Organisasi Dan Gaya Kepemimpinan Sebagai Variabel Moderating (Studi Empiris Pada Rumah Sakit di Pekanbaru). Jurnal SOROT. Vol. 8, No. 2 Oktober. Hal. 1-190.

Kusuma, Budi Hartono. 2016. Pengaruh Partisipasi penyusunan Anggaran Terhadap Kierja Manajerial: Komitmen Organisasi Sebegai VariabelMediasi. Jurnal Akuntansi. Vol. 8, No. 2, November 2016: 203-213.

Moheri, Yoyon., Arifah, Dista Amalia. 2015. Pengaruh Partisipasi Anggaran Terhadap Kinerja Manajerial. Jurnal Ekonomi dan Bisnis. Vol. 16, No. 1, Januari 2015, Hal. 86-93.

Setyorini, Ninik., Hasthoro, Handoko A., Wicaksono, Agung. 2013. Partisipasi Anggaran Pada Organisasi Sektor Publik. Jurnal Bisnis dan Ekonomi. Vo. 4, No. 2, Desember 2013, 137-148.

Siahaan, Victor D. 2010. Pengaruh Profesionalisme Terhadap Komitmen Organisasi Dalam Upaya Meningkatkan Kinerja Auditor (Studi Pada Kantor Perwakilan BPK-RI Provinsi Aceh). Jurnal Telaah \& Riset Akuntansi. Vol. 3, No. 1. Januari 2010. Hal.10-28.

Sinuraya, Candra. 2009. Pengaruh Partisipasi Penyusunan Anggaran dan komitmen Organisasi Terhadap Kepuasan Kerja dan Kinerja Karyawan. Jurnal Akuntansi, Universitas Kristen Maranatha, Volume 1 Nomor 1, mei 2003.

Smith \& Bertozzi . 1998. Principal Agent: An Explanatory model of public budgeting. Journal of Public Budgeting, Accounting and
Financial Manageent (fall). pp. 325-353.

Yusfaningrum, Kusnasriyanti., dan Ghozali, Imam. 2005. Analisis Pengaruh Partisipasi Anggaran Terhadap Kinerja Manajerial Melalui Komitmen Tujuan Anggaran dan Job Relevant Information (JRI) Sebagai Variabel Intervening (Penelitian Terhadap Perusahaan Manufaktur di Indonesia). Jurnal SNA VIII Solo, 15-16 September 2005. 